\title{
Osteochondral Allograft Transplantation in Professional Athletes: Rehabilitation and Return to Play
}

\author{
Snehal Patel, PT, MPT, SCS ${ }^{1}$, Arya Amirhekmat, BA², Ryan Le, BS², Riley J Williams III, MD³, Dean Wang, MD ${ }^{4}$ a \\ 1 Sports Rehabilitation Center, Hospital for Special Surgery, ${ }^{2}$ University of California Irvine School of Medicine, ${ }^{3}$ Sports Medicine Institute, Hospital \\ for Special Surgery, ${ }^{4}$ University of California Irvine School of Medicine; UCI Health \\ Keywords: physical therapy, return to sport, rehabilitation, osteochondral allograft transplantation
}

https://doi.org/10.26603/001c.22085

International Journal of Sports Physical Therapy

Vol. 16, Issue 3, 2021

For the treatment of large chondral and osteochondral defects of the knee, osteochondral allograft transplantation (OCA) is an effective solution with relatively high rates of return to sport. In professional athletes, rehabilitation following OCA is a critical component of the process of returning the athlete to full sports activity and requires a multidisciplinary team approach with frequent communication between the surgical and rehabilitation teams (physical therapists, athletic trainers, coaching staff). In this review, we describe our five-phase approach to progressive rehabilitation of the professional athlete after OCA, which takes into account the biological processes of healing and optimization of neuromuscular function required for the demands of elite-level sport. The principles of early range of motion, proper progression through the kinetic chain, avoidance of pain and effusion, optimization of movement, regimen individuation, and integration of sports-specific activities underlie proper recovery.

For the treatment of large chondral and osteochondral defects of the knee in young athletes, osteochondral allograft transplantation (OCA) is an effective solution that involves the single-stage transfer of viable, mature donor articular cartilage to replace diseased cartilage tissue. ${ }^{1}$ OCA has the advantage of providing a biomechanically functional hyaline cartilage surface that has the ability to bear joint loading immediately after transplantation. As a result, post-operative rehabilitation and return to activities after OCA may be accelerated compared to other cartilage repair strategies that implant immature cartilage tissue. Return to sport rates in athletes following OCA have been reported between $75-82 \%^{2-4}$ with return typically occurring at 8-12 months after surgery. ${ }^{5}$ These patients experienced a clinically significant improvement in pain, functionality, and activity levels as indicated by Knee Injury and Osteoarthritis Outcome Score (KOOS), Tegner, and Marx scores. ${ }^{2}$ As a result, OCA has become a mainstay of treatment in high level athletes.

Rehabilitation after OCA surgery can be difficult for any patient population but is particularly challenging for the professional athlete due to the requisite physical demands on the knee and psychological pressures involved in returning to sport at the same or higher level. The cartilage defects cause pain and kinetic movement dysfunction that af- fects these patients for a considerable amount of time prior to surgical intervention, and in turn make rehabilitation after surgical intervention difficult and frustrating for both the athlete and the rehabilitation specialist. When designing a rehabilitation program, it is essential for athletes to adhere to the entire rehabilitation process starting from date of surgery and extending through the return to full sport phase. Compliance with a home program is essential for consistent progress and the return of proper joint function. Should an athlete attend therapy session for three times a week for approximately one hour sessions, the supervised sessions only comprise about $2 \%$ of an entire 168 hour week; during the remaining $98 \%$ of time, the athlete is left responsible for personal rehabilitation. ${ }^{6}$ When planning rehabilitation with the professional athlete, functional demand is an important consideration. For example, the functional loading requirements for a professional basketball player varies greatly compared to a 45 -year-old recreational basketball player.

A common theme in the rehabilitation protocol is the need for the rehabilitation specialist to ensure the repaired tissue and joint are properly loaded throughout the rehabilitation process to prevent any delays in progressive load advancement. Despite the initial standardized timeline for biological healing, progression varies upon the athlete, ne-

\footnotetext{
a Corresponding Author:

Dean Wang MD

101 The City Dr S, Pav III, Bldg 29A

Orange, CA 92866

deanwangmd@gmail.com
} 
cessitating an individualized rehabilitation approach following surgery. Cautious progression should be utilized through criteria-based guidelines rather than fixed timebased guidelines in order to decrease rates of recurrent pain and/or joint effusion. Rehabilitation protocols vary widely for this surgical intervention with regard to weight bearing precautions, brace usage, exercise progression, progression criteria, and timeline for return to competitive activity. A number of these recommendations are based on the idea that rehabilitation protocols are dependent on the anatomic region repaired, patient-specific issues, and overall technical factors related to the surgical reconstruction. ${ }^{4-20}$ As such, rehabilitation following OCA is a critical component of the process of returning the professional athlete to full sports activity and requires a multidisciplinary team approach with frequent communication between the surgical and rehabilitation teams (physical therapists, athletic trainers, coaching staff). The following rehabilitation guidelines presented take into consideration the existing literature, current rehabilitation principles, and current basic science of osteochondral allograft integration after surgery (Table 1).

\section{REHABILITATION PHASE PROGRESSION}

\section{PHASE I: IMMEDIATE POST-SURGERY (WEEKS 0-2)}

Goals of this phase include reduction of pain and effusion, immediate ROM, and preliminary weight bearing through the joint. Weight bearing protocols after osteochondral allograft implantation is a topic of continuing discussion between surgeons, rehabilitation professionals, and the scientific community. Protocols vary greatly, ranging from immediate weight bearing to partial or non-weight bearing for 6 weeks to 3 months. ${ }^{7}$ However, numerous studies have expressed that overly aggressive weight bearing restrictions may overtax the allograft articular cartilage resulting in proteoglycan loss and deterioration of mechanical properties. ${ }^{9-11}$ A basic understanding of biological healing underlies the principle that proper tissue healing must occur in order to progress through the overall rehabilitation process. In the case of OCA, the graft is a composite of both a living mature hyaline cartilage and bone. Bone healing and integration via creeping substitution must occur in the early stages for the athlete. If the allograft bone does not integrate into the host bone, in vivo graft subsidence or delamination of the articular cartilage surface can occur as the graft sees higher loads. ${ }^{21}$ At the same time, it is known that moderate mechanical loading is healthy for articular cartilage of the knee as it promotes interstitial fluid flow in and out of the permeable collagen-proteoglycan matrix, facilitating the movement of nutrients from the synovial fluid into the collagen matrix and stimulating an anabolic chondrocyte reponse. ${ }^{7,9-11}$ At this time, there is a lack of consensus on the optimal post-operative weight bearing regimen after OCA, which is likely dependent on multiple factors, including the biochemical and mechanical properties of the transplanted graft at time zero and evolution of these properties during the early post-operative healing period, as well as the technical aspects of the transplant surgery (quality of press-fit fixation, topography of graft compared to host surface, etc). A recent study suggests that the surgeon's experience can influence their preferences regarding post-operative rehabilitation guidelines. ${ }^{8}$ In any case, the rehabilitation professional must have proper and frequent communication with the referring surgeon and an understanding of their specific protocol in order to properly monitor the athlete for signs of joint overload throughout the rehabilitation process. In OCA patients, our experience has been that early weight bearing ( $20 \%$ foot flat weight bearing for 1-2 weeks post-surgery, followed by progression to full weight bearing) has an advantageous effect in preventing further muscle atrophy and allowing earlier progression to functional and fitness activities. This accelerated protocol, however, is dependent on robust mechanical fixation of the graft during surgery. During the first 2 weeks after surgery, signs and symptoms such as swelling and pain should be closely monitored, and the rehabilitation program should be adjusted in these cases. During this initial phase, the athlete wears a knee brace locked in extension to minimize shearing forces on the knee joint during weight bearing and preventing subsequent graft damage. ${ }^{22}$

Immediate passive range of motion is permitted with the emphasis on attaining full knee extension as soon as possible. The avoidance of arthrofibrosis is also an important aspect of OCA rehabilitation. It is critical that the athlete gain early full extension because the inability to do so in the early stages can lead to gait abnormalities, patellofemoral symptoms, and higher level biomechanical dysfunction in the later phases of rehabilitation. ${ }^{23-26}$ The goal is to achieve at least 0 degrees of extension within the first week post-surgery. Heel props can be performed with a towel or roll placed underneath the heel, allowing gravity to apply a prolonged low-load stretch into extension. (Figure 1) This exercise should be performed frequently throughout the day in order to gain maximal extension. In addition to this, light stretching of the hamstring and gastrocnemius/soleus complex can help elongate posterior chain musculature, and enhance knee extension. Less emphasis is placed on achieving excessive knee flexion immediately after surgery, as the joint trauma from knee flexion can contribute to postoperative edema and pain. Passive ROM can provide neuromodulation of pain during acute conditions, but only when performed in a pain-free range ${ }^{27}$ Forced flexion ROM past its natural limits can lead to increased overall pain, inflammation or effusion, and can inhibit further gains in motion. If the athlete is able to gain flexion range of motion to 90 degrees without end range stiffness or tissue restrictions within the first 2 postoperative weeks, it is sufficient to progress the patient through the rehab process. If the patient is able to push past this amount without any increased symptoms, then flexion is not restricted, given the range of motion is passive, and not requiring any voluntary muscular contraction. An exception to this protocol is OCA for focal patellar osteochondral lesions. In these cases, ROM is usually restricted to 90 degrees over the first 2 to 4 weeks depending on the lesion size, location, and surgeon protocol in order to protect the allograft. ${ }^{28}$ 
Table 1: Summarized Rehabilitation Protocol

\begin{tabular}{|c|c|c|c|c|c|}
\hline Phase & Phase I: Weeks 0-2 & Phase II: Weeks 2-6 & Phase III: Weeks 6-12 & Phase IV: Weeks 12-20 & Phase V: Weeks 20+ \\
\hline Precautions & 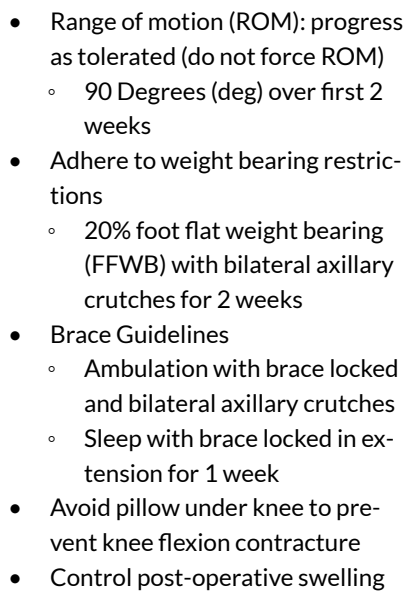 & $\begin{array}{l}\text { - Progress ROM as tolerated: do not } \\
\text { force motion } \\
\text { Weeks 2-4: partial weight bearing } \\
\text { up to 50\% with crutches } \\
\text { - Weeks 4-6: weight bearing as tol- } \\
\text { erated } \\
\text { - Brace guidelines: } \\
\text { - Weeks 2-4: Unlock brace when } \\
\text { proper quad control is established } \\
\text { Discharge brace at } 4 \text { weeks (may } \\
\text { use knee sleeve at this point, if } \\
\text { needed) } \\
\text { - Avoid pillow under knee to prevent } \\
\text { knee flexion contracture } \\
\text { - Control post-operative swelling }\end{array}$ & $\begin{array}{l}\text { - Progress to full ROM } \\
\text { - Avoid pain with therapeutic exercises } \\
\text { and functional activities } \\
\text { - Continue to control post-operative } \\
\text { swelling }\end{array}$ & $\begin{array}{l}\text { - Avoid pain with therapeu- } \\
\text { tic exercises and func- } \\
\text { tional activities } \\
\text { - Control post-operative } \\
\text { edema } \\
\text { - Monitor overall load and } \\
\text { volume }\end{array}$ & $\begin{array}{l}\text { - Avoid pain with advanced } \\
\text { strengthening, and plyo- } \\
\text { metric activity } \\
\text { - Avoid pain with progres- } \\
\text { sion of return to running } \\
\text { program } \\
\text { - Be cautious of } \\
\text { patellofemoral overload } \\
\text { with increased activity } \\
\text { level } \\
\text { - Continue to control post- } \\
\text { operative swelling } \\
\text { - Monitor overall load and } \\
\text { volume }\end{array}$ \\
\hline $\begin{array}{l}\text { ROM/ Soft } \\
\text { Tissue }\end{array}$ & $\begin{array}{l}\text { - Immediate ROM after surgery } \\
\text { - } \quad \text { Do not force ROM } \\
\text { - immedasize full knee extension } \\
\text { - Heel prop multiple times per day } \\
\text { - } \quad \text { Lower extremity stretching (ham- } \\
\text { string/gastrocnemius/soleus) } \\
\text { - Patellar mobilization as indicated } \\
\text { (all planes) }\end{array}$ & $\begin{array}{l}\text { - ROM goals (use as a guide) } \\
\therefore \text { Week } 3-0-105^{\circ} \\
\circ \text { Week } 4-0-115 / 120^{\circ} \\
\text { - Week 6- } 0-130^{\circ} \text { (progressing to } \\
\text { full ROM) } \\
\text { - Continue exercises from phase } 1 \\
\text { - Heel slides against wall (if difficulty } \\
\text { gaining ROM) } \\
\text { - Step knee flexion stretch, and supine } \\
\text { hip flexor stretch when tolerated } \\
\text { - Maintain passive knee extension and } \\
\text { patellar mobility } \\
\text { - Continue LE soft tissue treatment and } \\
\text { stretching as needed }\end{array}$ & $\begin{array}{l}\text { - Gradual increase of ROM to full ROM } \\
\text { - Continue exercises from phase } 2 \\
\text { - Prone knee flexion stretches } \\
\text { - Maintain full passive knee extension } \\
\text { - } \text { Continue patellar mobilization as } \\
\text { needed } \\
\text { - Continue with LE soft tissue program } \\
\text { - } \text { as needed } \\
\text { - } \quad \text { Contininue with LE stretching program } \\
\text { (hip, hamstring, gastrocnemius/soleus) } \\
\text { - Add hip flexor and quad stretching }\end{array}$ & $\begin{array}{l}\text { - Patient should demon- } \\
\text { strate full ROM without } \\
\text { limitations } \\
\text { - Continue LE soft tissue } \\
\text { treatment as needed }\end{array}$ & $\begin{array}{l}\text { - } \quad \text { Continued LE stretching } \\
\text { - Continued foam rolling } \\
\text { program } \\
\text { - } \\
\text { Adjunct with soft tissue } \\
\text { massage if needed }\end{array}$ \\
\hline Strength & $\begin{array}{l}\text { - Quadriceps re-education. } \\
\text { - Quad sets, straight leg raises } \\
\text { (SLR) with NMES } \\
\text { - SLR's (all planes) } \\
\text { - Emphasize no extension lag dur- } \\
\text { ing exercise } \\
\text { - initiate primary core stabiliza- } \\
\text { tion/Kinetic linking program } \\
\text { - Ab sets }\end{array}$ & $\begin{array}{l}\text { - Continue Quadriceps re-education } \\
\text { with NMES as needed } \\
\text { Continue blood flow restriction } \\
\text { (BFR) program if patient cleared } \\
\text { by MD } \\
\text { - Bilateral Leg Press } \\
60^{\circ} \rightarrow 0^{\circ} \text { arc (week 2-4) } \\
90^{\circ} \rightarrow 0^{\circ} \text { arc (week 4-6) } \\
\text { - Initiate core stabilization/Kinetic link- }\end{array}$ & $\begin{array}{l}\text { - Progress stationary bike time } \\
\text { - Initiate interval bike program between } \\
\text { weeks } 10-12 \text { for cardio } \\
\text { - Progress to elliptical } \\
\text { - Single leg pawing } \rightarrow \text { retrograde tread- } \\
\text { mill } \\
\text { - Multiplanar gluteal/core/hip strength- } \\
\text { - } \text { ening } \\
\text { - Continue exercises from phase II }\end{array}$ & $\begin{array}{l}\text { - Emphasize eccentric } \\
\text { strength and control } \\
\text { - Continue to progress with } \\
\text { squat program (PRE's) } \\
\text { - Continue to progress with } \\
\text { eccentric leg press (PRE's) } \\
\text { - Progress with suspension } \\
\text { training squats } \\
\text { - Eccentric DL squats (5/5/1 }\end{array}$ & $\begin{array}{l}\text { - Advanced strength pro- } \\
\text { gram 3-4 times/week } \\
\text { - Cardiovascular endurance } \\
\text { training with continued } \\
\text { low load methods } \\
\text { - Bike/elliptical/stair ma- } \\
\text { chine/ rower } \\
\text { - Glute activation exercises } \\
\text { - Chair/box squats }\end{array}$ \\
\hline
\end{tabular}




\begin{tabular}{|c|c|c|c|c|c|}
\hline Phase & Phase I: Weeks 0-2 & Phase II: Weeks 2-6 & Phase III: Weeks 6-12 & Phase IV: Weeks $12-20$ & Phase V: Weeks 20+ \\
\hline & $\begin{array}{l}\text { - Pelvic bracing } \\
\text { - } \text { BKFO } \\
\text { - Side lying clam shells } \\
\text { - } \\
\text { Ankle progressive resistive exer- } \\
\text { - Conses (PRE) } \\
\text { (BFR) program with FDA ap- } \\
\text { proved device and qualified ther- } \\
\text { apist if patient cleared by MD } \\
\text { - Independent with home exercise } \\
\text { program (HEP) that addresses } \\
\text { primary impairments }\end{array}$ & $\begin{array}{l}\text { ing program } \\
\text { - Standing bilateral heel raises-Week } \\
2-3 \\
\text { - Short Crank Bike progressing to up- } \\
\text { right bike with adequate ROM } \\
\text { (110-115 degrees of ROM) } \\
\text { - Multiplanar glute/Core/hip strength- } \\
\text { ening } \\
\text { - Bridges with t-band } \\
\text { - Standing clamshells } \\
\text { - Weight shift exercises with UE sup- } \\
\text { port } \\
\text { - Bilateral weight bearing propriocep- } \\
\text { tion exercises } \\
\text { - Single leg balance/proprioceptive ac- } \\
\text { tivities after proper quad control ob- } \\
\text { tained } \\
\text { - Hydrotherapy when incisions are } \\
\text { healed for gait, proximal strengthen- } \\
\text { ing, functional movements, balance } \\
\text { and edema control- week 4-6 } \\
\text { - Underwater treadmill/ anti-gravity } \\
\text { treadmill gait training if gait pattern } \\
\text { continues to be abnormal }\end{array}$ & 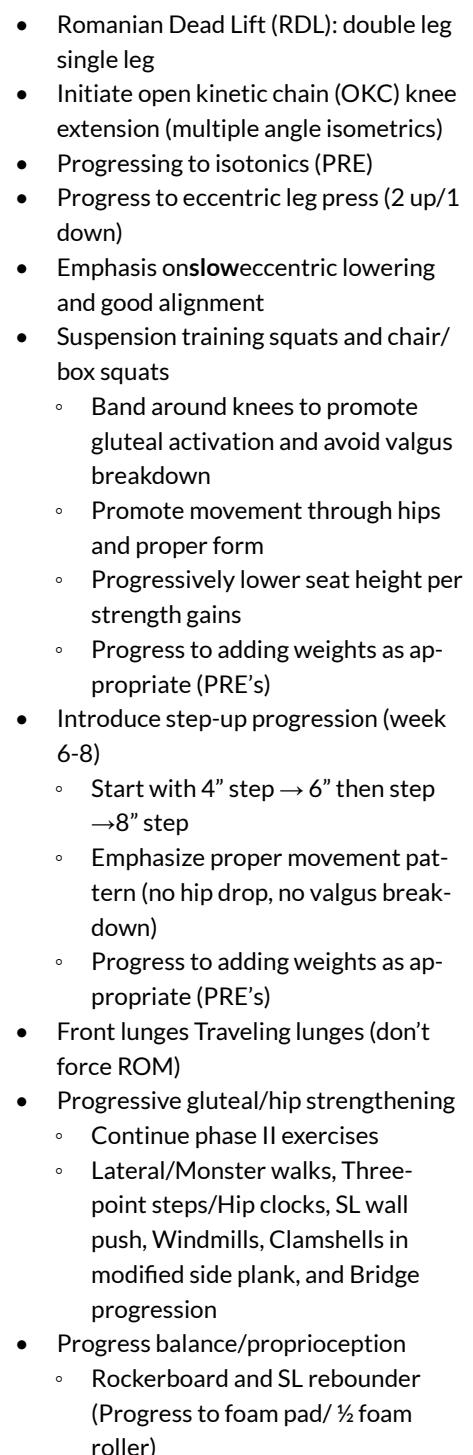 & $\begin{array}{l}\text { count) } \\
\text { - SL squats focusing on con- } \\
\text { trol and technique (proper } \\
\text { hip hinge pattern) } \\
\text { - Progress with interval bik- } \\
\text { ing for endurance/fitness } \\
\text { (time and resistance) } \\
\text { - Progress with step-ups/ } \\
\text { downs by increasing } \\
\text { height and adding weight } \\
\text { (intrinsic load) } \\
\text { - Advanced proprioception } \\
\text { training (perturbations) } \\
\text { - Continue to progress with } \\
\text { aquatic program if avail- } \\
\text { able } \\
\text { - Stair master/Versaclimber } \\
\text { - Continue with kinetic link- } \\
\text { ing/core progression } \\
\text { - Continue with LE stretch- } \\
\text { ing } \\
\text { - Progress isotonic knee ex- } \\
\text { tension OKC - progress to } \\
\text { isokinetics: moderate to } \\
\text { high speeds } \\
\text { - Initiate running progres- } \\
\text { sion with Anti-gravity } \\
\text { treadmill or pool running- } \\
\text { weeks } 16-18 \\
\text { Must have good eccen- } \\
\text { tric control with } 8 \text { " step } \\
\text { down } \\
\text { Be cautious of over- } \\
\text { loading the knee - mon- } \\
\text { itor for swelling }\end{array}$ & $\begin{array}{l}\text { - Leg press (DL/SL) } \\
\text { - Eccentric leg press with } \\
\text { proper control and } \\
\text { alignment } \\
\text { - Multiplanar hip strength- } \\
\text { ening } \\
\text { - Front/side/back lunges } \\
\text { - RDL (DL/SL) } \\
\text { - Advanced kinetic linking } \\
\text { progression } \\
\text { - Chops/lifts } \\
\text { - LE stretching/foam rolling } \\
\text { program } \\
\text { - Plyometric program (DL } \\
\text { SL) } \\
\text { - Individualized per sport } \\
\text { and patient need } \\
\text { - Progress strength and } \\
\text { flexibility through entire } \\
\text { kinetic chain (hips, knees, } \\
\text { ankle) } \\
\text { - Agility and balance drills } \\
\text { - Progress with sport spe- } \\
\text { cific programs } \\
\text { - Return to running program } \\
\text { at month } 6 \\
\text { - Must have good eccentric } \\
\text { control with 8" step down } \\
\text { - Progress with interval } \\
\text { treadmill program (moni- } \\
\text { tor knee load) } \\
\text { - Cardiovascular training } \\
\text { - Bike/eliptical/Rower/ } \\
\text { - Versaclimber } \\
\text { - } \text { Gnaerobic interval } \\
\text { craining } \\
\text { cises } \\
\text { Chair/box squats } \\
\text { o Double leg (5/5/1) } \\
\text { Modified SL (eccentric } \\
\text { control) }\end{array}$ \\
\hline
\end{tabular}




\begin{tabular}{|c|c|c|c|c|c|}
\hline Phase & Phase I: Weeks 0-2 & Phase II: Weeks 2-6 & Phase III: Weeks 6-12 & Phase IV: Weeks $12-20$ & Phase V: Weeks 20+ \\
\hline & & & $\begin{array}{l}\text { - Sports specific balance } \\
\text { - Core/kinetic linking progression } \\
\text { - Progress BFR program to more weight } \\
\text { bearing activities (i.e. squats, leg press) } \\
\text { - Introduce eccentric step-down pro- } \\
\text { gram (week 8-12) } \\
\text { - Start with 4" step } \rightarrow 6 \text { " step } \rightarrow 8 \text { " } \\
\text { step (assisted with railing) } \\
\text { - Emphasize proper movement pat- } \\
\text { tern (no hip drop, no valgus break- } \\
\text { down) } \\
\text { - Progress to adding weights as ap- } \\
\text { propriate (PRE's) }\end{array}$ & & $\begin{array}{l}\text { - } \text { Multiplanar hip strength- } \\
\text { ening } \\
\text { - } \text { Front/side/back lunges } \\
\text { - SL Runners RDL }\end{array}$ \\
\hline $\begin{array}{l}\text { Criteria for } \\
\text { advancing }\end{array}$ & $\begin{array}{l}\text { - Maintain knee ROM: 0-90 deg } \\
\text { - Control post op pain/swelling } \\
\text { - SLR flexion without extensor lag } \\
\text { - } \text { Adherence to post-op restric- } \\
\text { tions } \\
\text { - Independent with HEP }\end{array}$ & $\begin{array}{l}\text { - Full weight bearing with crutches, dis- } \\
\text { - } \text { charge brace } \\
\text { - } \text { wemonstrate a normal gait pattern } \\
\text { - Progressing toward } \\
\text { - Normal patellar mobility (all planes) } \\
\text { - Proximal strength }>4 / 5 \\
\text { - Minimal edema } \\
\text { - Well controlled pain } \\
\text { - Independent with progressive HEP }\end{array}$ & $\begin{array}{l}\text { - Full pain-free ROM } \\
\text { - Chair/box squats with proper form and } \\
\text { without complaints of pain } \\
\text { - SL stance > } 30 \text { sec with proper form } \\
\text { and control } \\
\text { - Demonstrate ability to ascend 8" step } \\
\text { with proper form, no pain } \\
\text { - Descend 6" step with good eccentric } \\
\text { control, no pain } \\
\text { - Independent with HEP }\end{array}$ & $\begin{array}{l}\text { - } 80 \% \text { limb symmetry } \\
\text { (quadriceps and ham- } \\
\text { string) with handheld dy- } \\
\text { namometry and functional } \\
\text { testing } \\
\text { - No pain/inflammation af- } \\
\text { ter activity } \\
\text { - Movement without asym- } \\
\text { metrical deviations and a } \\
\text { hip dominant strategy } \\
\text { - Independent with HEP }\end{array}$ & $\begin{array}{l}\text { - } 90 \% \text { limb symmetry } \\
\text { (quadriceps and ham- } \\
\text { string) with handheld dy- } \\
\text { namometry and functional } \\
\text { testing } \\
\text { - } \quad \text { Isokinetic test } \geq 90 \% \text { limb } \\
\text { symmetry (if available) } \\
\text { - } \quad \text { Independent with gym } \\
\text { strengthening and mainte- } \\
\text { nance program } \\
\text { - } \text { Movement without asym- } \\
\text { metrical deviations and a } \\
\text { hip dominant strategy } \\
\text { - Lack of apprehension with } \\
\text { sports specific movement } \\
\text { (eg. acceleration/decelera- } \\
\text { tion, cutting) }\end{array}$ \\
\hline
\end{tabular}


Immediate patellar mobility is a mainstay during this phase to reduce the amount of scar tissue that can develop post-surgically. The loss of patellar mobility may result in ROM complications along with difficulty recruiting proper quadriceps contraction. Often times, patellar mobilization is not adequately prioritized in the rehabilitation process, and the potential lack of mobility can lead to a loss of motion in the knee joint. Superior mobility of the patella is required for full knee extension, and inferior mobility is required for full knee flexion. ${ }^{29}$ The athlete should be instructed to perform this frequently throughout the day in order to obtain maximal patellar mobility. ${ }^{30}$ Soft tissue manipulation of lower extremity musculature post-operatively can also help with edema control. Attention should be given to soft tissue manipulation along the suprapatellar and infrapatellar pouch to facilitate overall patellar mobility and ease with ROM.

Restoration of quadriceps control is imperative in this phase of rehabilitation to aid in early strengthening. In the context of the professional athlete, this restoration of symmetric muscle function is a key aspect in a successful return to sport. This restoration should be initiated as early as post-operative day 1 in order to gain volitional quadriceps control, and aid in reducing knee edema and pain through the activation of the natural muscle pump. The use of electrical stimulation for quadriceps activation is encouraged in this phase, and has been shown to facilitate return of volitional muscle activation as well. ${ }^{31,32}$ Due to the limited weight bearing status of the patient, exercises are limited to those such as quadriceps sets, and straight leg raises. An adjunct that can be used at this stage to help increase quadriceps strength is the addition of blood flow restriction.

Blood flow restriction (BFR) training can elicit positive muscle hypertrophy and strength adaptations in load compromised populations using light external loads of $20-30 \%$ 1 rep max. ${ }^{33,34}$ Although the application of BFR on patients who undergo cartilage transplants has not been heavily researched, its usage early on with electrical stimulation has been documented with the post ACL population with positive results. ${ }^{35}$ This presumably is due to the fact that it has been shown to decrease overall pain and effusion of the joint. This has been well documented in patients with knee osteo arthritis, patellofemoral pain and in-patient military personnel. ${ }^{33,36-39}$ The overall effect of exercise in populations with musculoskeletal conditions can be attenuated in the presence of pain due to a detrimental effect on motor control and muscle function and can lead to compensations and modified movement patterns. ${ }^{40}$ The usage of BFR early on has a two-fold effect in that it helps the overall reduction of pain and swelling, along with improving overall muscle hypertrophy working at lower loads, as to not irritate the healing joint complex. The enhancement of quadriceps activation and hypertrophy early on can have tremendous effects as the rehabilitation process progresses.

Along with activation of the quadriceps musculature, a preliminary development of core stabilization should be initiated during this phase. Athletic movement is dependent on the synergistic work of the entire kinetic chain, with the proximal musculature, including the hips and abdominal region, having a major role in linking the upper and lower kinetic chain. ${ }^{41,42}$ At times, core activation and

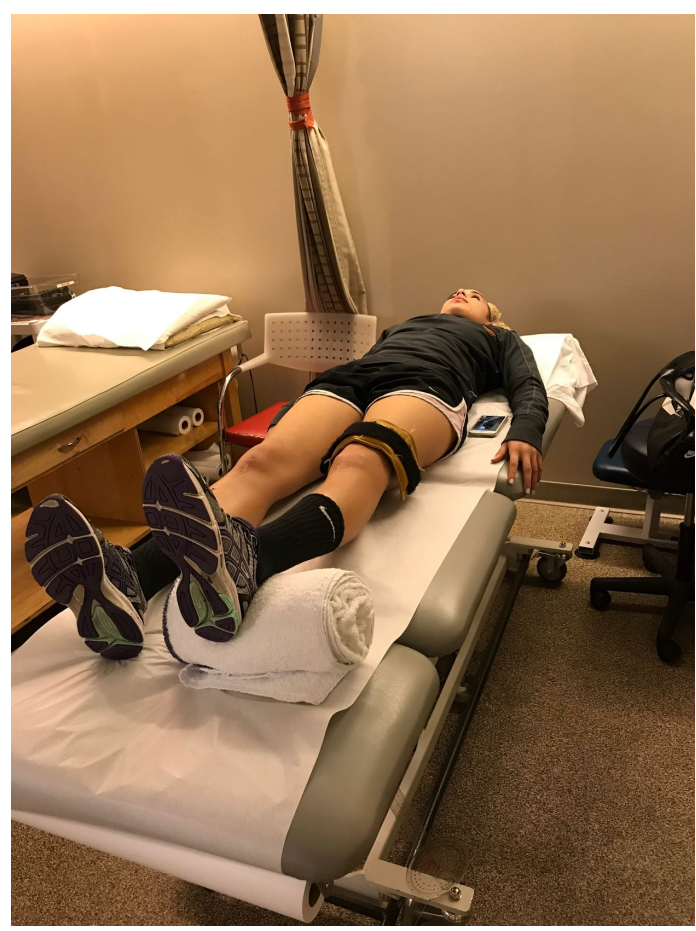

Figure 1: Passive knee extension on raised towel to promote immediate full knee extension

stabilization is neglected due to the majority of emphasis being placed on regaining lower extremity function and control. Exercises such as abdominal and pelvic bracing, side lying clamshells, and bilateral knee fall outs can help with activation of core musculature early in the rehabilitation process. It is important to understand that return to sport starts from post-operative day one. Ensuring that the athlete is engaged not only in lower extremity rehabilitation, but also reconditioning of their entire body throughout the process allows for timely progression, and a more readily return to sport at their optimal performance level while decreasing risk for re-injury.

Edema and pain control are important during the entire rehabilitation, but especially during these early phases. The benefits of cryotherapy for edema and pain control are well documented in the literature. Numerous studies have reported a progressive decrease in volitional quadriceps activity as the knee exhibits increased pain and distension. ${ }^{43-45}$ The usage of cryotherapy is essential to minimizing reflex inhibition, and restoration of normal quadriceps function. Studies showing usage of an active compression cold therapy system after anterior cruciate ligament reconstruction resulted in significant increased range of motion and functional knee scores compared to cold therapy alone. ${ }^{46}$ The usage of an active compression cold therapy unit is usually used for at least the first two weeks to maximize the benefits early on. Along with this, the athlete can benefit from a commercial knee sleeve or compression wrap to apply constant pressure and edema control during functional activities. 
PHASE II: WEEKS 2-6

During this second phase of rehabilitation, the repaired tissue is healing and gaining strength, but it is still not quite mature. This transition phase can last up to 12 weeks following surgery. ${ }^{29}$ The goals of this phase are to normalize gait and progress to full active and passive motion of the knee complex. ROM can be progressed from Phase I with passive knee stretching along with early utilization of a stationary bike. Biking can start with a short crank $(90 \mathrm{~mm})$ bicycle when knee flexion approaches 90 degrees, with subsequent use of a standard upright stationary bike for ROM progression once knee flexion improves to $\sim 110$ degrees. Caution should be taken not to aggressively force flexion ROM, which may result in increased pain, effusion and unwarranted inflammation. Early strengthening, with adherence to weight bearing progression, is advanced in this stage as well. Athletes can begin with bilateral leg press in a shortened arc (60 degree to 0 degree) with progression to 90 degree to 0 degree arc as ROM progresses.

Weight bearing should be advanced specific to surgeon protocol, but in a stepwise pattern in order to reduce adverse swelling and pain that may result from overaggressive loading and rapid increases in stress to the graft. A typical weight bearing progression begins with immediate toe touch weight bearing (20\%), progressing to partial weight bearing $(50 \%)$ with bilateral axillary crutches, transitioning to $75 \%$ weight bearing using a single axillary crutch, and finally weight bearing as tolerated while weaning off the assistive device. Balance training during this phase begins with weight shift exercises using upper extremity support and progressing to single leg balance/proprioceptive exercises as proper quad control is obtained. A proper gait pattern is imperative during the beginning stages to reduce subsequent gait abnormalities. Emphasis should be placed upon proper knee extension during heel strike, along with proper quadriceps activation and control during the stance phase. During the swing phase of the gait cycle, the athlete should be cued on proper knee flexion to avoid subsequent gait abnormalities. However, until proper quadricep control is noted, the athlete is typically using a brace locked in extension to assist joint stability in the absence of quadriceps control. At times, prolonged usage of a brace can lead to a gait pattern where the athlete circumducts the hip during swing phase. Occasionally, this gait pattern can persist when the brace is removed. The resulting abnormal gait pattern may lead to hip or lower back pain secondary to muscular compensation. Hence, gaining quadricep control early on is imperative for a proper gait pattern and timely discontinuation from brace usage. Exercises such as a hurdle step-over can be introduced at this time to educate proper quadricep activation during ambulation and enhance reciprocal patterning that is important during the later phases of rehabilitation. (Figure 2) In most athletes, a normal gait pattern will be developed, but in certain cases, gait deviations can persist late in this phase of rehabilitation. In these cases, utilization of an underwater treadmill or anti-gravity treadmill can aid in reducing the load of the affected lower extremity and facilitate a proper gait pattern.

Once quadricep activation is achieved, the athlete should switch their focus on regaining independent neurological function. The use of biofeedback in this patient population has shown positive outcomes in enhancing volitional quadriceps contraction. ${ }^{47}$ The achievement of terminal knee extension is paramount in this patient population because normal arthrokinematics of the knee is required for a proper gait pattern, and more importantly, proper athletic movement. Abnormal joint arthrokinematics can predispose an athlete to increased patellofemoral and/or tibiofemoral joint contact forces resulting in increased pain, and potentially the inability to fully load the joint for athletic movement in later phases of rehabilitation. ${ }^{24,48}$ The addition of biofeedback at this phase enhances quadriceps control mitigating a quadriceps inhibited or flexed knee gait pattern. The sooner normal arthrokinematics of the knee joint occur, the sooner rehabilitation can progress.

The athlete should continue to progress with core stabilization at this phase. Athletic movement requires the proper linking of the lower and upper body for optimal athletic movement. The traditional model of the kinetic chain states that the human body is made up of a series of integrated links or segments (parts of a whole). ${ }^{49}$ It is a coordinated action of these body segments that allow optimal movement, generating power from ground reaction forces that are subsequently transferred to the final length of the chain. Introduction of kinetic chain linking progressions can start early on in the rehabilitation process and can help the athlete develop proper force generation in the later phases of rehabilitation. Intermuscular myofascial connections such as the superficial back line, deep front line, and spiral line (along with others) can impact overall force transmission and stability to the body during dynamic movements such as running, throwing and jumping. ${ }^{50,51}$ Integration of exercises such as double leg bridging with a band around the knees to facilitate glute activation, modified and normal front planks along with modified side planks can help activate the posterior, anterior, and lateral planes which will be imperative in building a foundation for athletic movement. (Figure 3) These aspects can be started early on, but choosing the correct exercises is important so as to not put excessive joint pressure through the knee and healing graft during this phase.

Aquatic therapy may be a beneficial adjunct to therapy in the later phases of this phase. This is introduced only when the incision is completely healed, which normally occurs around 4-6 weeks post-operatively. The addition of aquatics can help the athlete progress with activities that they would normally not be able to do on land secondary to weight bearing restrictions. Exercises such as double leg squat, hip clock, and advanced ambulation exercises can be performed as the buoyancy of water decreases weight bearing forces. Weight bearing can be reduced to up to $25 \%$ of an athlete's body weight when submerged to the axilla. ${ }^{52,53}$ Early initiation of controlled exercises in the pool can help the athlete return to functional activities sooner, and boost psychological morale in the athlete as well. The sooner the progression to regular functional activity, the sooner the athlete feels they are mentally prepared for returning to their sport.

The loss of function with a significant knee injury, as well as inability to participate in their sport can be psychologically difficult for the athlete, and often times can lead to an altered emotional state. Although it is early in the re- 

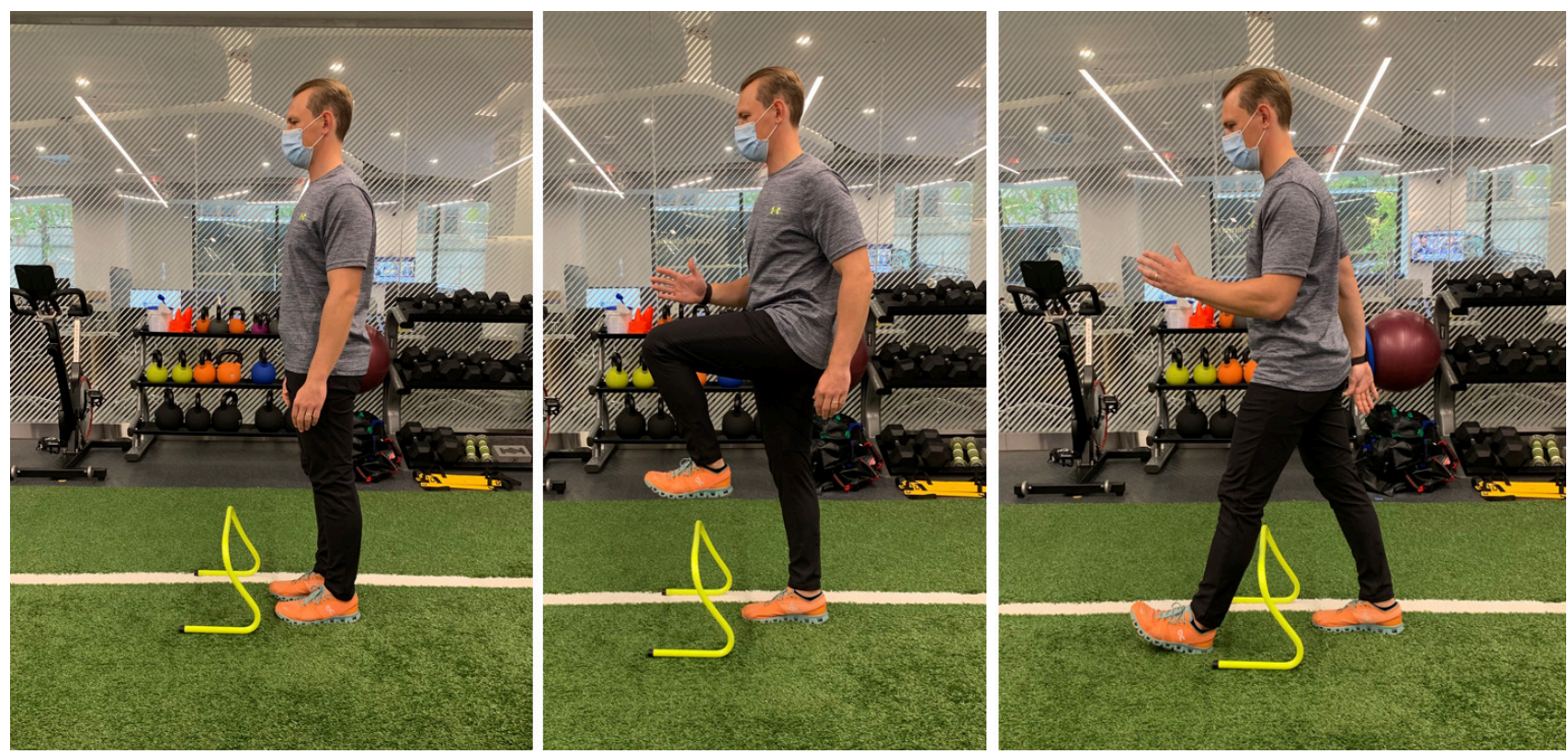

Figure 2: Single hurdle step over to aid with proper gait: (a) starting position, (b) Maximal knee flexion with opposite arm flexion, (c) ending position of heel strike and quad contraction

hab process, it is valuable for the athlete to participate in some modification of their sport to remain connected in a positive way. Having a basketball player perform seated ball handling and shooting activities or having a tennis player perform seated forehand shots can allow for a smooth transition back to in game mechanics. Initiating such activities such in this stage can help them on their mental journey of returning to sport.

\section{PHASE III: WEEKS 6-12}

This next transition phase of rehabilitation focuses on progressive strengthening, and typically lasts until 12 weeks post-operatively. ${ }^{54-57}$ Strengthening in this phase should transition to exercises that progressively load the knee joint. Careful consideration must be taken in this phase of rehabilitation as the athlete resumes most activities of daily living. Most athletes with osteochondral defects have experienced chronic pain associated with their lesions, as it is a common occurrence for this patient population to delay receiving definitive treatment. Because of this, the aspect of pain had been prevalent in their everyday activities before, and thus the idea of "some pain is normal" continues to be in their mindset. In this phase of rehabilitation, the athletes' pain continues to dissipate, and they may want to return to their sport sooner than recommended. Proper education should be addressed with the athlete, placing an emphasis on the biologic healing required to take place in conjunction with progressive strengthening and conditioning necessary for a proper and safe progression. Multiplanar gluteus and hip strengthening should be introduced at this phase as weight bearing precautions and protocol allows. Examples of exercises emphasizing these muscles groups include standing hip clocks with band resistance, and lateral or monster walks. (Figure 4) Constant cues should be given to athletes regarding proper loading and proper joint
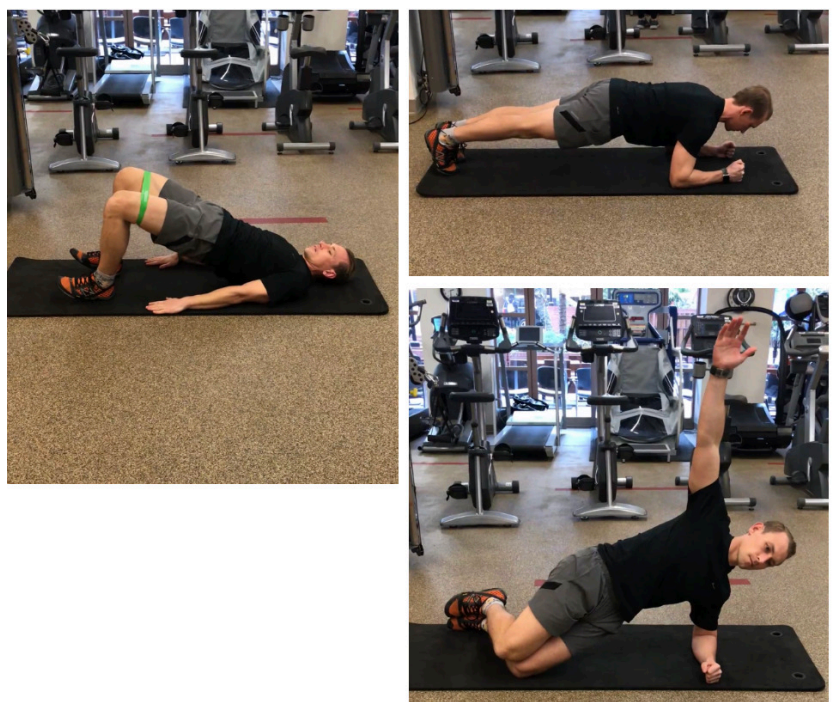

Figure 3: Preliminary Kinetic linking: (a) DL bridge with band abduction, (b) front plank, (c) modified side plank

alignment during these exercises. Valgus breakdown of the knee during these static exercises must be addressed with verbal and tactile cues; otherwise, these habits may persist during dynamic exercises in later phases. Valgus breakdown and subsequent improper movement patterns can lead to pain and discomfort in the knee, and often, frustration by the athlete due to lack of or slower progression in the rehabilitation program. Body weight squats can also be initiated in this phase with special focus on the movement pattern utilized. Athletes should be taught a proper hip hinge pattern permitting proper loading through the hips and proximal musculature to decrease pressure and load of 

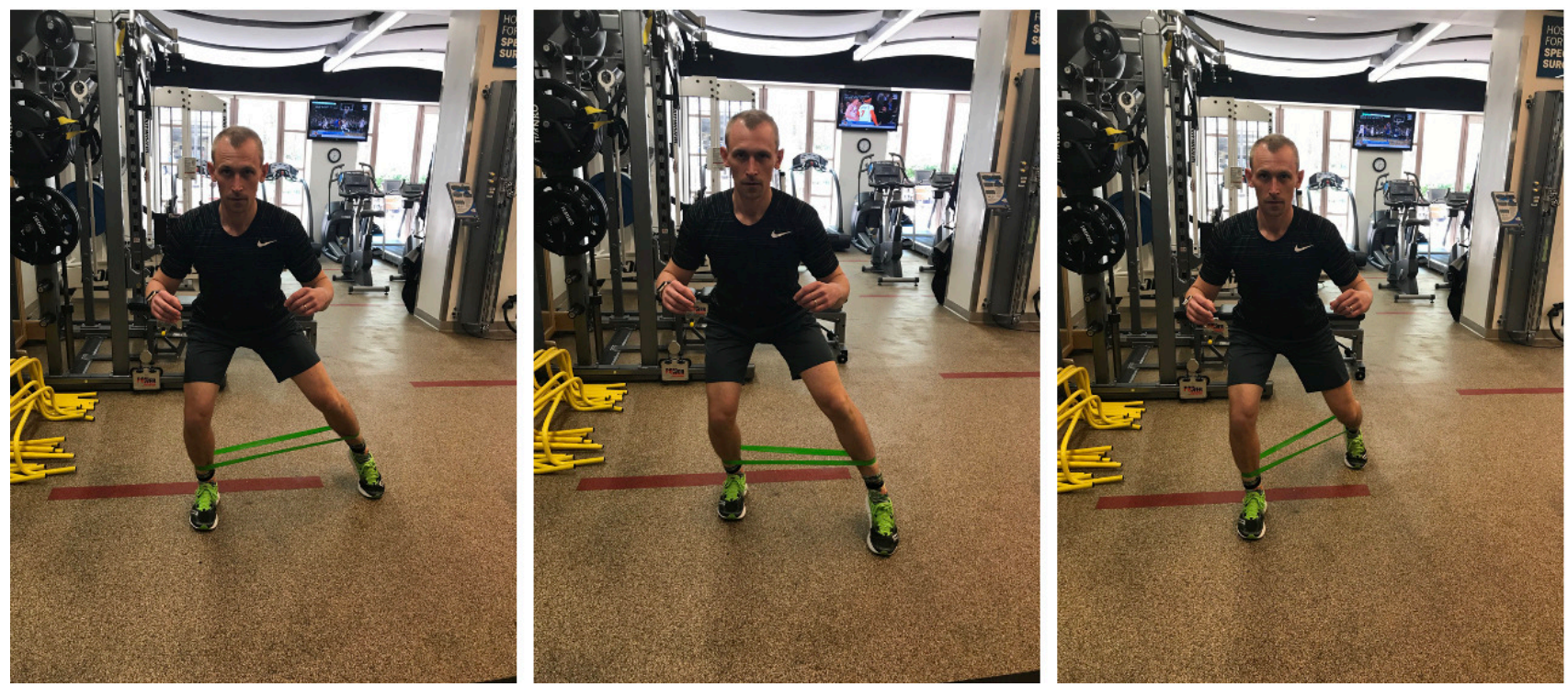

Figure 4: Standing hip clocks with band resistance

the knees. (Figure 5) During this phase, leg press emphasizing slow single leg eccentric control should be introduced. Kinematic analysis of the knee joint during jumping activities shows that the highest peak load across articular cartilage occurs with the knee in the fully extended position. Loading decreases as the joint goes into the flexed position, during which controlled eccentric flexion distributes the applied load and protects the articular cartilage and intra-articular structures. ${ }^{58-61}$ Teaching this eccentric control and enhancing the eccentric quadriceps strength is imperative in these athletes to help them realize that increasing this strength can help them decrease abnormal joint pressures and subsequent knee pain with progressive activities. This eccentric training should be continued throughout the rehabilitation process following this phase, as it has been shown to improve plyometric activities as well. As this phase progresses, single leg strengthening should also be introduced. Exercises such as front and side lunges, unilateral leg press, and single leg Romanian dead lifts can be utilized. Focus should be placed on slow eccentric control during these motions, along with keeping proper form throughout the exercise. (Figure 6) Athletes with an osteochondral lesion likely had been training with knee pain to a certain extent. Due to this pain and discomfort they have developed compensation mechanisms to complete exercise and training tasks, which can persist after the post-surgical process. ${ }^{62-64}$ It is essential for these athletes to use visual and tactile cues to perform these exercises with proper form and reduce the compensation mechanisms that have been engrained in their movement patterns. The post-operative rehabilitation program should involve the gradual progression of applied and functional stresses to provide a healthy stimulus for healing tissues without causing subsequent damage to the new graft. ${ }^{29}$

Full ROM should be attained in this phase through continued use of the stationary bike along with hip flexor and quadricep stretching. The athlete should be encouraged to stretch and mobilize often throughout the day to avoid forceful manipulation of the knee joint and subsequent

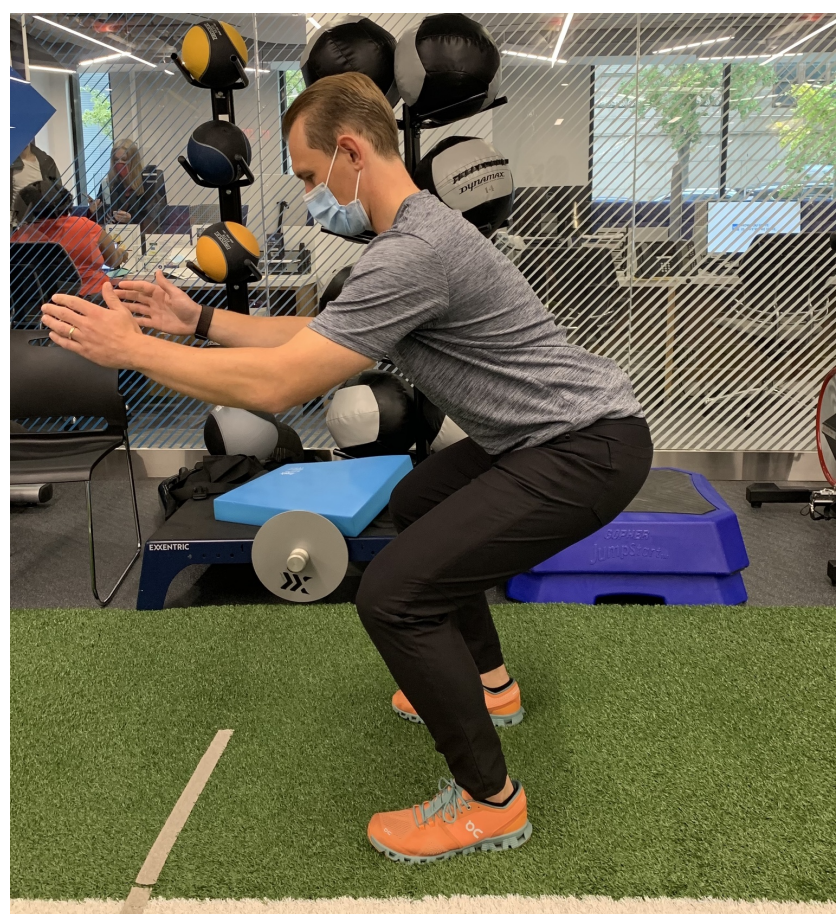

Figure 5: Proper hip hinge pattern for double leg squat

joint effusion. As this phase progresses, and normal active and passive ROM is achieved, the athlete can begin with self-directed soft tissue release techniques such as foam rolling and myofascial release. Progression through a foam rolling program can help improve flexibility of the lower extremities and in turn facilitate further gains in strength. ${ }^{65,66}$ The majority of athletes with focal chondral lesions have decreased lower extremity strength and more importantly a lack of single leg strength simply due to the fact of having progressive pain with strengthening exercises. The subsequent strength loss in these athletes can 
lead to a "guarding" mechanism in the knee, which can be demonstrated by a flexed knee gait pattern, general lower extremity tightness, and increased tone around the knee joint and lower extremity. Teaching a proper foam rolling program can help decrease this tone, and increase overall proprioception so that proper movement patterns can be learned. 67

Lower limb based cardiovascular training should also be introduced early in this phase. As mentioned previously, athletes can demonstrate significant emotional disturbances and depression with significant knee injuries. There is ongoing evidence that shows the use of aerobic exercise multiple times a week can help decrease these disturbances. ${ }^{68}$ The constant high speed starting, stopping, and acceleration that is required in sports such as basketball or soccer involves a large demand on the anaerobic system. ${ }^{69}$ This system should be activated early on in the rehabilitation process allowing for a progressive advancement, rather than a delayed initiation in later phases of rehabilitation. Early-phase cardiovascular training should focus on the upper extremities. Examples include seated upper body ergometer, seated versaclimber, or use of a fan bike with upper extremities only. TABATA training is an effective anaerobic training method that can be implemented early in the process. ${ }^{70,71}$ This regiment includes 4 minutes of total exercise performed in intervals of 20 seconds of high intensity, followed by 10 seconds of rest (a total of 8 rounds is performed). Due to the continued healing in the graft, athletes are not able to train their cardiovascular system at a level to which they are accustomed. Early cardiovascular training with the upper extremities exercises this system, as well as their overall competitive nature. Low-load stationary biking with minimal resistance can be initiated around the 8-week mark. Initially, the athlete should progress with the total time of their sessions and be educated to not over work the knee joint which may cause increased edema, and possibly pain. An interval biking program progressing with speed and resistance can be started around the 8-10 weeks, provided the athlete has had no initial complaints with progressive increases in time. If a pool is available, aqua jogging in deep water can be initiated as a form of cardiovascular exercise and has shown to have good increases in anaerobic training as well. ${ }^{72}$ This can help facilitate a proper running pattern and provide a foundation for the later phases of running. More recently, there has been an increased awareness of the significant emotional components associated with athletes who suffer knee injuries. Anxiety and depression are common factors that occur when an athlete cannot participate in their sport after a knee injury. ${ }^{73,74}$ These feelings can be compounded in high level collegiate or professional athletes in whom their participation in sport may be essential to their livelihood. There is a mounting group of studies demonstrating that the use of aerobic exercise multiple times a week can mitigate these emotions in athletes. ${ }^{68}$ Many times these cardiovascular gains are focused on in the later phases of rehabilitation, but in the professional athlete's case, cardiovascular gains that can be achieved safely should be started at this phase to ensure that optimal physical fitness gains can be achieved throughout the process.

Continuing to develop kinetic chain linking procedures
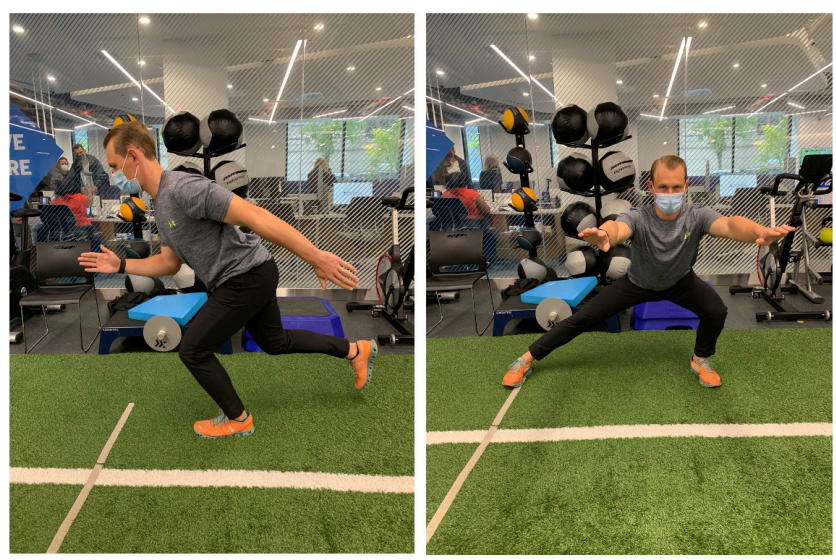

Figure 6: Proper hip hinge pattern to decrease pressure on knee joint (a) single leg RDL, (b) side lunge/Cossack squat

in this phase is important so the athlete can learn to properly dissipate forces through the repaired knee joint and transfer force throughout the entire kinetic chain instead of heavily relying on the knee complex. Once optimal core activation is developed on the ground in phase 2 , the decision has to be made to progressively transition to a more functional standing position, remembering that sequential activation has to be achieved before advancing to complex athletic movement. For example, a palloff press variation series can be implemented with either band or weighted resistance. Having the athlete move to a standing position challenges the body in the frontal (core timing/activation), sagittal (core strength), and transverse planes (rotational stability). (Figure 7) Doing this while maintaining standing trains the athletes to transmit forces from a stable base through the trunk and to the upper extremities for optimal force output.

Progression of proprioceptive exercises is important for this population as well. ${ }^{75-77}$ Double leg proprioceptive exercises should be progressed by using an unstable surface such as a BOSU ball or rocker board to challenge stability. Single leg balance should also be progressed by adding external perturbations and unstable surfaces. With all sporting activities, movement is unpredictable and random. This idea should be incorporated into proprioceptive activities, reiterating the idea that the athlete is working on a return to sport during all phases of rehabilitation.

\section{PHASE IV: 12-20 WEEKS}

Remodeling of the graft tissue starts during this phase and can last up to 6-12 months postoperatively. ${ }^{54-57}$ During this time frame, there is a continuous remodeling and integration of the OCA to resemble the pre-injury articular surface. ${ }^{54-57}$ This clinically correlates with the progression of overall training activities as most athletes approach a pain-free state. Movement education such as proper hip hinge pattern for basic DL lower leg strengthening activities (i.e. deadlifts, squats) are reinforced in this phase. Frequent movement assessments should be monitored as rehabilitation progresses. These assessments can range from a sim- 

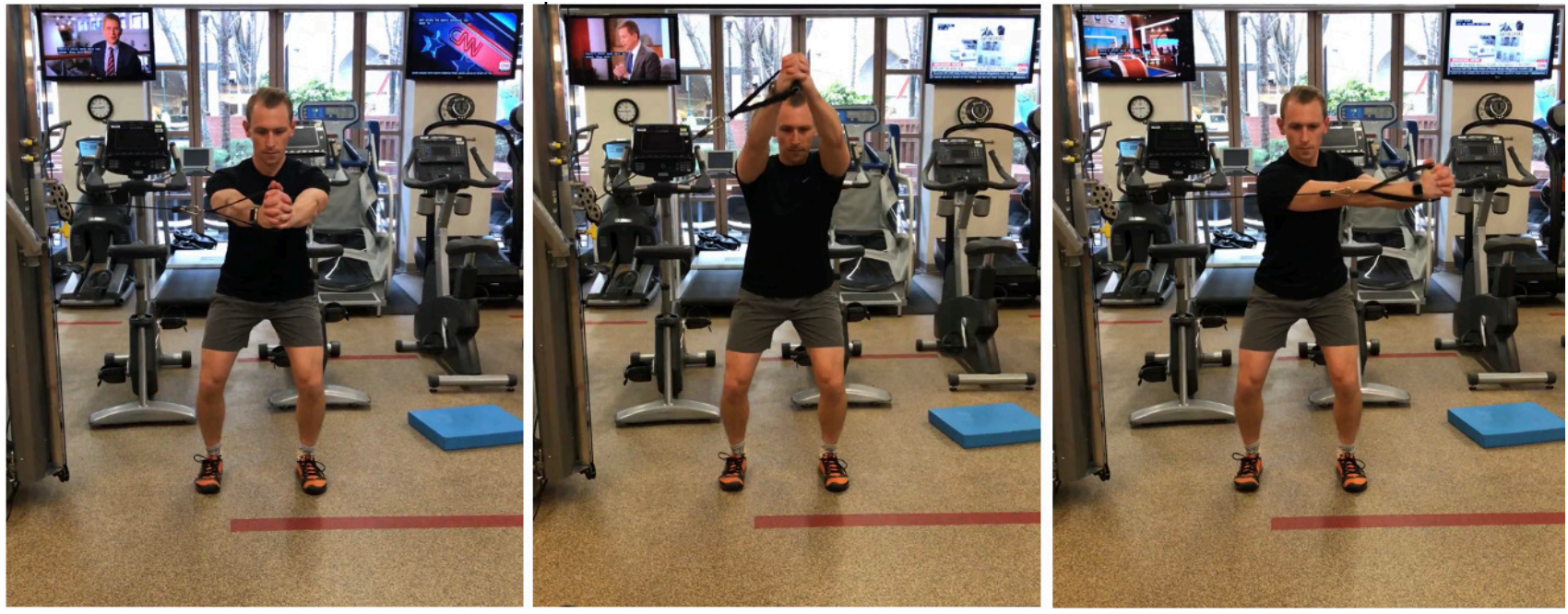

Figure 7: Pallof Press variation: (a) frontal plane (core activation), (b) sagittal plane (core strength), (c) transverse plane (rotational stability)

ple visual assessment of movement patterns to biomechanical analysis using a motion capture system. Although the joint is structurally repaired at this point and pain continues to improve, athletes may have developed altered movement patterns that became ingrained in their neuromuscular system. These discrepancies can continue to be present unless they are observed in a qualitative and quantitative manner and corrected previously during the rehabilitation process. A movement assessment for the athlete can help identify weaknesses in the kinetic chain, and aid in the development of a global plan to allow the athlete for a more efficient return to their sport. ${ }^{58}$

Strength becomes a primary target during this phase. In previous phases, pain may have limited the athlete's ability to perform strength training exercises. Eccentric strength losses, especially in the affected lower extremity must be improved during this phase to support the allograft. A muscle's force-producing capacity is optimized when an external force exceeds that of the muscle while the muscle lengthens. Hence, the potential to improve muscle strength by overloading the muscle tissue is greater with eccentric strengthening than with concentric strengthening. ${ }^{59}$ The addition of single leg strengthening can be added, as long as the athlete does not have adverse effects such as effusion or pain during or after the exercise. Exercises such as single leg squats should also be progressed, continuing to stress the utilization of a proper hip hinge pattern. Furthermore, it may be beneficial to start with a modified supported single leg squat utilizing a yoga block, medicine ball, or a suspension system (TRX). (Figure 8) Leg press should also be progressed with weight in both the concentric and eccentric portion of strengthening. Eccentric step downs should be introduced as another method of eccentric quadricep strengthening with progressive joint loading. The athlete should be constantly educated on progression of exercise with weights and repetition while also considering load education. ${ }^{78}$ As the affected limb continues to strengthen, the increases in strength will in turn help them load the joint more. Athletes should be educated that although they have
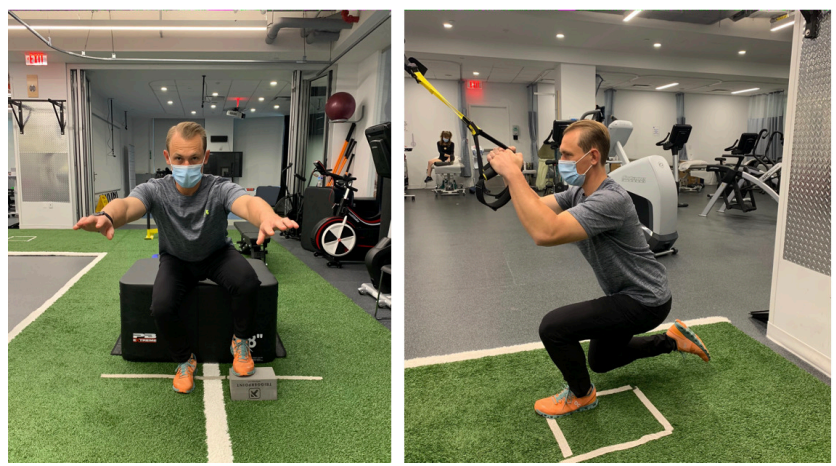

Figure 8: Single leg squat progressions (a) block underneath foot to decreased weight bearing on that side, (b) Suspension system assisted single leg squat

progressed well to this point, they should continue to monitor the overall load on their knee to prevent any persistent effusion or pain.

Cardiovascular exercises should be progressed at this time to include a variety of different exercise platforms. Trying to overcome the deconditioning that occurred over the first 12 weeks must be addressed so the athletes can progress back to sports in the final stage of rehabilitation. Athletes should continue to be encouraged to use the stationary bike and progress their interval biking program, increasing resistance and time. Elliptical training, stairmaster, and versaclimber can also be used to improve cardiovascular conditioning. Anaerobic training can also be progressed at this time with the methods mentioned before. To exercise the competitive nature of the athlete, implementing leaderboards or partner training may be effective in improving the overall psyche of the athlete as they progress with return to sport. A common question is when to start a running program. In many cases, athletes feel that the only way they can start to transition to normality is if they can begin to run. Running may have been a signifi- 
cant source of pain preoperatively, therefore initiation of a running program may serve as a significant milestone and motivation for the athlete's return to sport. Typically, returning to high intensity running is not warranted until 6-8 months depending on the surgeon protocol. ${ }^{79-81}$ The use of an anti-gravity treadmill (Alter-G treadmill) can be initiated near the 4-5 month mark as long as the athlete demonstrates good eccentric quadricep strength in order to attenuate the forces produced while running. A simple objective measure that can be used to measure adequate eccentric strength is whether or not the athlete descend an 8 " step with good control and without movement deviations (trunk lean, hip drop, knee valgus). If an athlete is able to demonstrate this, and there has been sufficient healing of the graft site determined by the surgeon, then a return to running program can be safely started.

The progression of kinetic chain linking principles should continue to progress in this phase. Enhancing the athlete's ability to load with a stable single leg while having good core control is important to be able to eventually transfer their weight while performing explosive movements such as sprinting, pushing, hitting or throwing. However, the athlete should be able to maintain stability on a single leg with anti-rotational core stabilization before weight transfer and explosive movements are performed. A focus should be placed on trying to strengthen the entire kinetic chain and identifying any potential weaknesses at this point. (Figure 9) One potential method for identifying these deficiencies includes quantitative isokinetic testing which provides an objective measure for the athlete's strength. The athlete's ability to physically see the deficits in strength that remain when compared to a cohort group can have an impact on where they stand in their progression to return to full activity.

Modified sport activities may be reintegrated during this phase. For example, a basketball player can initiate ball handling drills and light form shooting on the court at this time, transitioning to light layup drills by the end of this phase. For tennis players, light forehand and backhand swings can be done in a static position, and transition into light lateral movements by the end of the phase. Load management is always a consideration with adverse effects of pain and or swelling potentially occurring as increasing loads are placed either too fast or too frequently. If these symptoms occur, further strengthening needs to occur before progressing with these activities.

\section{PHASE V: WEEKS $20+$}

The main goals of this phase are to regain high levels of proprioception, neuromuscular control, strength, and fitness with the intent to return to previous levels of athletic activity. ${ }^{80}$ The overall goal for any athlete is to not only to return to their sport, but to return to their sport at the highest level possible. As activity is increased during this phase to include progressive plyometric activity and agility training, caution should still be taken on potentially overloading of the patellofemoral joint with increased activity. ${ }^{82}$ Athletes need to continue to be diligent with their lower extremity strength gains in this phase allowing for proper support of their knee joint with higher level activities. An advanced
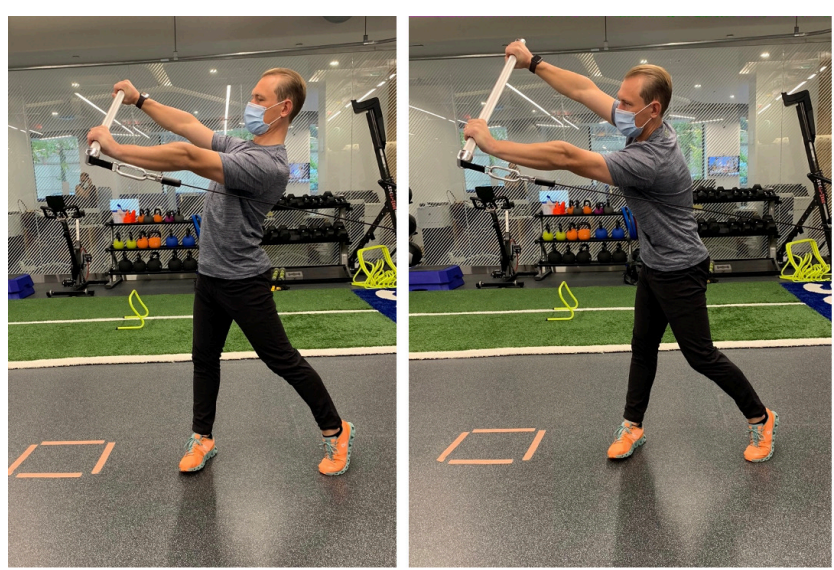

Figure 9: Kinetic change breakdown: (a) poor kinetic chain linking with an upward cable lift; notice the rib flare and increased low back lordosis, (b) proper kinetic linking with stable core to dissipate force throughout the kinetic chain

strength program consisting of aspects of cardiovascular training with continued low load methods (stationary bike, fan bike, Elliptical, stairmaster, versaclimber, row machine), progressive glute strengthening, DL and SL squatting activities, core strengthening, and advanced kinetic linking (cable or band chops and lifts) is critical for athletes to reach the final phase of returning to sport. Proper plyometric technique needs to be fortified in this phase as well. Having the athlete learn how to properly generate force with their lower extremities, and more importantly, land in a safe manner will help them protect the knee joint and prevent any deleterious effects of advanced training. The progressive eccentric quadricep training up to this point allows the athlete to be ready for these higher-level impact activities.

We routinely obtain a magnetic resonance imaging (MRI) assessment at 6 months to assess graft morphology. Osseous integration is not expected to be complete at this time. ${ }^{83}$ However, at 6 months, the allograft should show an intact articular cartilage surface, progressive bony incorporation with evidence of cross trabeculae, and no joint effusion (Figure 10). These objective measures, along with good movement, sufficient quadriceps control, and minimal (<20\%) side-to-side strength differences, form our basis for permitting athletes to start high-impact activities such as running and other sport-specific tasks. Progression should be in a planned and organized manner, so the athlete has specific stages to progress through with the goal of returning to the field of play. Activities should start with planned non-reactive drills (cone drills, set passing drills) and progress to unplanned reactive drills. While extra precautions should be taken for contact sports during this phase, play on the field may be initiated with non-contact scrimmage, progressing to contact scrimmage, and lastly, controlled live play. When these steps are completed and proper loading and confidence is seen in the athlete, along with no signs of deleterious effects on the knee joint, the athlete can progress to full game play.

Overall load management should be monitored as the athlete starts to participate in full game play activity. A re- 
striction on minutes played during a game may have to be instituted in order to progress to long game play situations. Athletes should be educated in this phase that as they start to progress with on field or on court activities, they will inherently be loading their joint more. Excessive running or jump training should be avoided since increased load is placed on the joint with a return to athletic activities. It is the surgeon and rehabilitation professionals' responsibility at this point to not only provide proper education to the athlete regarding load management, but to be the one to decide if the athlete can handle more activity and are cleared for return to sport. This last phase is a fluid process and is dependent on the overall gains that the athlete has made up to this point. It requires a conversation between the physical therapist, surgeon, team and athlete regarding when this phase is finished. Emphasis should be placed on criteria achieved for full contact return to sport and not just a time frame of biological healing.

\section{RETURN TO PLAY CONSIDERATIONS AFTER OCA}

The literature on return to play rates after OCA in professional athletes is sparse. In our series of collegiate and professional basketball players, we found a median return to competitive play at 14 months and an overall rate of return to play at the same level of competition at $80 \% .59$ Other studies that include high level athletes report return to sport rates ranging between $75-88 \%$ (Table 2). In professional athletes, the decision to return to play requires a multidisciplinary team approach with frequent communication between the surgical and rehabilitation teams (physical therapists, athletic trainers, coaching staff). The rehabilitation team needs to make sure that aspects of strength, movement and fitness are achieved. It is pertinent to note that not all athletes are built the same, and not all sports have the same physical demands. The physical demand for a baseball pitcher is different from a guard in basketball. Similarly, the efficiency of kinetic linking is different among sports as well. Athlete-specific care has to be integrated, and factors such as the specific sport and specific position played are ultimately considerations that the rehabilitation team need to consider. Isokinetic or general strength testing should show at least $90 \%$ limb symmetry between both legs before a return to sport is considered. More importantly, movement symmetry must also be present in which symmetry between sides is noted. Movement screens, functional sport testing, and jump testing are all quantitative elements that should be used in the return to sport process to safely and effectively return an athlete to their particular sport. ${ }^{84}$ As with any progression back to sport, athletes may experience soreness or persistent joint inflammation as progressive load is placed on the joint. A distinction needs to be made in athletes in this phase of when the soreness is happening. Is the overload happening with overtraining with plyometrics, or happening with progression of sports-specific activities? Throughout the rehabilitation process, the athlete had been taught and progressed through proper kinetic linking strengthening and progressions so that they understand that it is the job of the entire body to dissipate forces and not just the knee joint. Keeping these principles in mind during higher level strength and

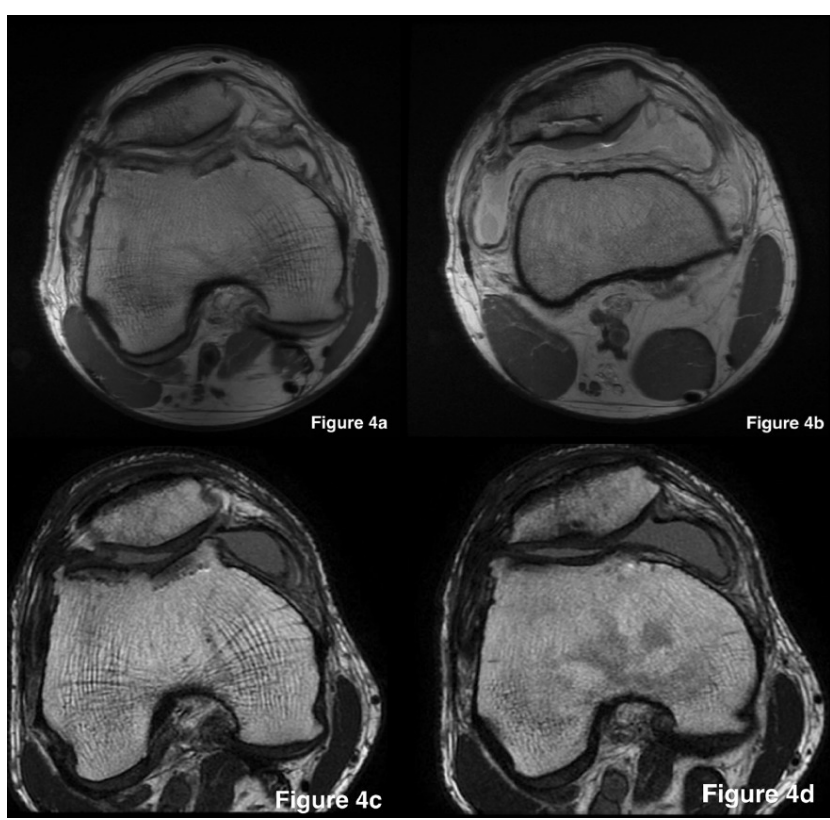

Figure 10: Axial magnetic resonance imaging (MRI) on postoperative day one after OCA of the (A) trochlea (2 dowels) and (B) patella in a professional basketball player. At 6 months, repeat axial MRI shows interval osseous integration of dowels in the (C) trochlea and (D) patella with maintenance of the articular cartilage surface reconstitution.

training activities can reduce the overall force that is placed on the knee complex but can also reduce further injury to other parts of the body. Joint inflammation after OCA can also be related to a low-level immunoreactivity of the host to the allograft tissue. Although articular cartilage is traditionally thought to be "immunoprivileged," antigenic material in the allograft bone, as well as exposed allogeneic chondrocytes, which express class I and II major histocompability (MHC) antigens, can potentially elicit immune responses in the host intra-articular environment. These persistent joint effusions can be particularly vexing for athletes during their recovery, Anti-inflammatory treatment modalities and limiting joint loads until complete resolution of the effusion are recommended. Future investigation into therapies that optimize the biologic milieu of the knee after transplantation are much needed.

Management of expectations of both the athlete and coaches will prevent overtraining. As athletes continue to progress, they may feel that they can do all the strengthening and plyometric activities that their teammates do. An understanding must take place that they are continuing to progress through the rehabilitation process and that patience has to be shown in order to continue to progress. Proper fitness gains finally have to be made in order for the athlete to be in "game shape" as well. Many athletes feel that as the rehabilitation process ends, they are automatically cleared for returning to full game play. Per our experience, athletes typically need 3-4 months of fitness training before being able to return to preinjury performance. Some of this involves continued strength training with the help of a strength and conditioning specialist as well as progress- 
Table 2: Return to Sport After Osteochondral Allograft Transplantation

\begin{tabular}{|c|c|c|c|c|c|c|}
\hline $\begin{array}{l}\text { Study } \\
\text { Author } \\
\text { (Year } \\
\text { Published) }\end{array}$ & $\begin{array}{l}\text { Number of } \\
\text { Patients } \\
\text { (Average Age } \\
\text { in years) }\end{array}$ & Level of Activity & $\begin{array}{l}\text { Average } \\
\text { Time to } \\
\text { Return to } \\
\text { Sport (in } \\
\text { months) }\end{array}$ & $\begin{array}{l}\text { Percentage } \\
\text { that } \\
\text { Returned to } \\
\text { Sport }\end{array}$ & $\begin{array}{l}\text { IKDC } \\
\text { prior to } \\
\mathrm{OCA}^{* *}\end{array}$ & $\begin{array}{l}\text { IKDC } \\
\text { after } \\
\text { OCA }\end{array}$ \\
\hline $\begin{array}{l}\text { Nielsen, E. } \\
\text { Scott, et } \\
\text { al. } \\
(2017)^{3}\end{array}$ & 142 (31.2) & $\begin{array}{l}\text { Self-reported: } 45 \% \\
\text { "highly competitive } \\
\text { athlete", } 55 \% \text { "well- } \\
\text { trained and } \\
\text { frequently sporting" }\end{array}$ & $\begin{array}{l}4 \text { to } 6 \text { per } \\
\text { protocol }\end{array}$ & $75.2 \%$ & $\begin{array}{l}42.0 \pm \\
16.5\end{array}$ & $\begin{array}{l}74.5 \pm \\
19.8\end{array}$ \\
\hline $\begin{array}{l}\text { Frank, } \\
\text { Rachel M., } \\
\text { et al. } \\
(2017)^{85}\end{array}$ & $180(32.7)$ & $\begin{array}{l}33 \% \text { Self-reported } \\
\text { athletes }\end{array}$ & $\begin{array}{l}4 \text { to } 6 \text { ( } 8 \\
\text { to } 12 \text { for } \\
\text { combined } \\
\text { surgeries) } \\
\text { per } \\
\text { protocol }\end{array}$ & $\begin{array}{l}63 \% \text { not } \\
\text { requiring } \\
\text { reoperation, } \\
87 \% \text { graft } \\
\text { survival }\end{array}$ & $33.8 \pm 13$ & $\begin{array}{l}59.2 \pm \\
21.4\end{array}$ \\
\hline $\begin{array}{l}\text { Balazs, } \\
\text { George C., } \\
\text { et al. } \\
(2018)^{59}\end{array}$ & $11(22.8)$ & $\begin{array}{l}64 \% \text { NCAA, } 36 \% \\
\text { NBA }\end{array}$ & $\begin{array}{l}\text { NBA } \\
\text { median } \\
20, \text { NCAA } \\
\text { median } 8\end{array}$ & $80 \%$ & $\begin{array}{l}\text { Not } \\
\text { Reported }\end{array}$ & $\begin{array}{l}\text { Not } \\
\text { Reported }\end{array}$ \\
\hline $\begin{array}{l}\text { Krych, } \\
\text { Aaron J., } \\
\text { et al. } \\
(2012)^{4}\end{array}$ & $43(32.9)$ & $\begin{array}{l}74 \% \text { recreation, } 23 \% \\
\text { NCAA, } 2 \% \\
\text { professional }\end{array}$ & $\begin{array}{l}\text { Average } \\
9.6 \\
\text { months } \pm \\
3.0 \\
\text { months }\end{array}$ & $\begin{array}{l}88 \% \text { limited } \\
\text { participation, } \\
79 \% \text { full } \\
\text { participation }\end{array}$ & $\begin{array}{l}46.27 \pm \\
14.86\end{array}$ & $\begin{array}{l}79.29 \pm \\
15.53\end{array}$ \\
\hline $\begin{array}{l}\text { McCarthy, } \\
\text { Mark A., } \\
\text { et al. } \\
(2017)^{61}\end{array}$ & $\begin{array}{l}13 \\
\text { (Unreported) }\end{array}$ & $\begin{array}{l}69 \% \text { Highschool, 31\% } \\
\text { NCAA }\end{array}$ & $\begin{array}{l}7.9 \pm 3.5 \\
\text { months }\end{array}$ & $77 \% * * *$ & $38 \pm 12$ & $63 \pm 22$ \\
\hline $\begin{array}{l}\text { Marmon, } \\
\text { Niv et al. } \\
(2019)^{86}\end{array}$ & 1 & 100\% Professional & 7 & $100 \%$ & $\begin{array}{l}\text { Not } \\
\text { Reported }\end{array}$ & $\begin{array}{l}\text { Not } \\
\text { Reported }\end{array}$ \\
\hline
\end{tabular}

* If time to return to sport data not provided, rehabilitation guidelines per protocol were listed

** IKDC=International Knee Documentation Committee Score; All IKDC improvements significant to $\mathrm{p}<0.014$

***** $77 \%$ when adjusted for patients who graduated from high school sport

****** Individual RTS data not provided for athletes, statistics represent entire cohort

ing with overall training of their particular sport. A continued team approach with the rehabilitation professional, strength coach and team is critical to ensure a proper progression back to sport.

\section{SUMMARY}

As OCA becomes more widely utilized to treat focal cartilage defects of the knee in high-level and professional athletes, post-operative rehabilitation is an essential component of the treatment plan in permitting athletes to re- turn to play. The aforementioned five-phase approach to progressive rehabilitation takes into account the biological processes of healing and optimization of neuromuscular recovery required for high-level sport. Even after proper progressive rehabilitation, persistent joint inflammation and reactivity remain a vexing issue for athletes after OCA. The principles of early ROM, proper progression through the kinetic chain, avoidance of pain and effusion, optimization of movement, regimen individuation, and integration of sports-specific activities underlie proper recovery.

Submitted: March 01, 2021 CDT, Accepted: April 06, 2021 CDT 


\section{REFERENCES}

1. Pearsall AW, Tucker JA, Hester RB, Heitman RJ. Chondrocyte viability in refrigerated osteochondral allografts used for transplantation within the knee. The American Journal of Sports Medicine. 2004;32(1):125-131.

2. Crawford ZT, Schumaier AP, Glogovac G, Grawe $\mathrm{BM}$. Return to sport and sports-specific outcomes after osteochondral allograft transplantation in the knee: A systematic review of studies with at least 2 years' mean follow-up. Arthroscopy: The Journal of Arthroscopic \& Related Surgery.

2019;35(6):1880-1889.

3. Nielsen ES, McCauley JC, Pulido PA, Bugbee WD. Return to Sport and Recreational Activity After Osteochondral Allograft Transplantation in the Knee. Am J Sports Med. 2017;45(7):1608-1614. doi:10.1177/0 $\underline{363546517694857}$

4. Krych AJ, Robertson CM, Williams RJ III, Cartilage Study Group. Return to athletic activity after osteochondral allograft transplantation in the knee. The American journal of sports medicine. 2012;40(5):1053-1059.

5. Krych AJ, Pareek A, King AH, Johnson NR, Stuart MJ, Williams RJ III. Return to sport after the surgical management of articular cartilage lesions in the knee: a meta-analysis. Knee Surg Sports Traumatol Arthrosc. 2017;25(10):3186-3196. doi:10.1007/s00167-016-426 2-3

6. Cavanaugh JT. Rehabilitation strategies following articular cartilage surgery in the knee. In: Cartilage Repair Strategies. Springer; 2007:343-369.

7. Kane MS, Lau K, Crawford DC. Rehabilitation and postoperative management practices after osteochondral allograft transplants to the distal femur: a report from the Metrics of Osteochondral Allografts (MOCA) Study Group 2016 Survey. Sports health. 2017;9(6):555-563.

8. Behrens F, Kraft EL, Oegema Jr TR. Biochemical changes in articular cartilage after joint immobilization by casting or external fixation. Journal of Orthopaedic Research. 1989;7(3):335-343.

9. Haapala J, Arokoski J, Pirttimäki J, et al. Incomplete restoration of immobilization induced softening of young beagle knee articular cartilage after 50 -week remobilization. International journal of sports medicine. 2000;21(01):76-81.
10. Vanwanseele B, Lucchinetti E, Stüssi E. The effects of immobilization on the characteristics of articular cartilage: current concepts and future directions. Osteoarthritis and Cartilage. 2002;10(5):408-419.

11. Emmerson BC, Görtz S, Jamali AA, Chung C, Amiel D, Bugbee WD. Fresh osteochondral allografting in the treatment of osteochondritis dissecans of the femoral condyle. The American journal of sports medicine. 2007;35(6):907-914.

12. Garrett JC. Fresh osteochondral allografts for treatment of articular defects in osteochondritis dissecans of the lateral femoral condyle in adults. Clinical Orthopaedics and Related Research ${ }^{\circledR}$. 1994;303:33-37.

13. LaPrade RF, Botker J, Herzog M, Agel J.

Refrigerated osteoarticular allografts to treat articular cartilage defects of the femoral condyles: a prospective outcomes study. JBJS. 2009;91(4):805-811.

14. Levy YD, Görtz S, Pulido PA, McCauley JC, Bugbee WD. Do fresh osteochondral allografts successfully treat femoral condyle lesions? Clinical Orthopaedics and Related Research ${ }^{\circledR}$. 2013;471(1):231-237.

15. McCulloch PC, Kang RW, Sobhy MH, Hayden JK, Cole BJ. Prospective evaluation of prolonged fresh osteochondral allograft transplantation of the femoral condyle: minimum 2-year follow-up. The American journal of sports medicine. 2007;35(3):411-420.

16. McDermott AG, Langer F, Pritzker KP, Gross AE. Fresh small-fragment osteochondral allografts. Longterm follow-up study on first 100 cases. Clinical orthopaedics and related research. 1985;(197):96-102.

17. Williams RJ III, Ranawat AS, Potter HG, Carter T, Warren RF. Fresh stored allografts for the treatment of osteochondral defects of the knee. JBJS. 2007;89(4):718-726.

18. Brown D, Shirzad K, Lavigne SA, Crawford DC. Osseous integration after fresh osteochondral allograft transplantation to the distal femur: a prospective evaluation using computed tomography. Cartilage. 2011;2(4):337-345.

19. Bugbee WD, Convery FR. Osteochondral allograft transplantation. Clinics in sports medicine. 1999;18(1):67-75. 
20. Chu CR, Convery FR, Akeson WH, Meyers M, Amiel D. Articular Cartilage Transplantation: Clinical Results in the Knee. Clinical Orthopaedics and Related Research (1976-2007). 1999;360:159-168.

21. Rauck RC, Wang D, Tao M, Williams RJ. Chondral Delamination of Fresh Osteochondral Allografts after Implantation in the Knee: A Matched Cohort Analysis. Cartilage. 2019;10(4):402-407. doi:10.1177/1 $\underline{947603518777576}$

22. DeVita P, Hortobagyi T. Functional knee brace alters predicted knee muscle and joint forces in people with ACL reconstruction during walking. Journal of applied biomechanics. 2001;17(4):297-311.

23. Perry J, Antonelli D, Ford W. Analysis of kneejoint forces during flexed-knee stance. JBJS. 1975;57(7):961-967.

24. Irrgang JJ, Harner CD. Loss of motion following knee ligament reconstruction. Sports Medicine. 1995;19(2):150-159.

25. Benum P. Operative mobilization of stiff knees after surgical treatment of knee injuries and posttraumatic conditions. Acta Orthopaedica Scandinavica. 1982;53(4):625-631.

26. Matsusue Y, Yamamuro T, Hama H. Arthroscopic multiple osteochondral transplantation to the chondral defect in the knee associated with anterior cruciate ligament disruption. Arthroscopy: The Journal of Arthroscopic \& Related Surgery. 1993;9(3):318-321.

27. Salter RB, Hamilton HW, Wedge JH, et al. Clinical application of basic research on continuous passive motion for disorders and injuries of synovial joints: a preliminary report of a feasibility study. Journal of orthopaedic research. 1983;1(3):325-342.

28. Blankevoort L, Kuiper JH, Huiskes R, Grootenboer HJ. Articular contact in a three-dimensional model of the knee. Journal of biomechanics.

1991;24(11):1019-1031.

29. Reinold MM, Wilk KE, Macrina LC, Dugas JR, Cain EL. Current concepts in the rehabilitation following articular cartilage repair procedures in the knee. Journal of Orthopaedic \& Sports Physical Therapy. 2006;36(10):774-794.

30. Manske RC, Prohaska D, Lucas B. Recent advances following anterior cruciate ligament reconstruction: rehabilitation perspectives. Current reviews in musculoskeletal medicine. 2012;5(1):59-71.
31. Snyder-Mackler L, Delitto A, Stralka SW, Bailey SL. Use of electrical stimulation to enhance recovery of quadriceps femoris muscle force production in patients following anterior cruciate ligament reconstruction. Physical therapy. 1994;74(10):901-907.

32. Delitto A, Rose SJ, McKowen JM, Lehman RC, Thomas JA, Shively RA. Electrical stimulation versus voluntary exercise in strengthening thigh musculature after anterior cruciate ligament surgery. Physical therapy. 1988;68(5):660-663.

33. Hughes L, Paton B, Rosenblatt B, Gissane C, Patterson SD. Blood flow restriction training in clinical musculoskeletal rehabilitation: a systematic review and meta-analysis. British Journal of Sports Medicine. 2017;51(13):1003-1011.

34. Lixandrao ME, Ugrinowitsch C, Berton R, et al. Magnitude of muscle strength and mass adaptations between high-load resistance training versus lowload resistance training associated with blood-flow restriction: a systematic review and meta-analysis. Sports medicine. 2018;48(2):361-378.

35. Hughes L, Rosenblatt B, Paton B, Patterson SD. Blood flow restriction training in rehabilitation following anterior cruciate ligament reconstructive surgery: A review. Techniques in Orthopaedics. 2018;33(2):106-113.

36. Giles L, Webster KE, McClelland J, Cook JL. Quadriceps strengthening with and without blood flow restriction in the treatment of patellofemoral pain: a double-blind randomised trial. British Journal of Sports Medicine. 2017;51(23):1688-1694.

37. Ferraz RB, Gualano B, Rodrigues R, et al. Benefits of resistance training with blood flow restriction in knee osteoarthritis. Med Sci Sports Exerc. 2018;50(5):897-905.

38. Bryk FF, Dos Reis AC, Fingerhut D, et al. Exercises with partial vascular occlusion in patients with knee osteoarthritis: a randomized clinical trial. Knee Surgery, Sports Traumatology, Arthroscopy. 2016;24(5):1580-1586.

39. Ladlow P, Coppack RJ, Dharm-Datta S, et al. Lowload resistance training with blood flow restriction improves clinical outcomes in musculoskeletal rehabilitation: a single-blind randomized controlled trial. Frontiers in physiology. 2018;9:1269.

40. Herrington L, Al-Sherhi A. A controlled trial of weight-bearing versus non-weight-bearing exercises for patellofemoral pain. journal of orthopaedic \& sports physical therapy. 2007;37(12):155-160. 
41. Sciascia A, Cromwell R. Kinetic chain rehabilitation: a theoretical framework. Rehabilitation research and practice. 2012;2012.

42. McMullen J, Uhl TL. A kinetic chain approach for shoulder rehabilitation. Journal of athletic training. 2000;35(3):329.

43. Horvath SM, Hollander JL. Intra-articular temperature as a measure of joint reaction. The Journal of clinical investigation. 1949;28(3):469-473.

44. Osbahr DC, Cawley PW, Speer KP. The effect of continuous cryotherapy on glenohumeral joint and subacromial space temperatures in the postoperative shoulder. Arthroscopy: The Journal of Arthroscopic \& Related Surgery. 2002;18(7):748-754.

45. Spencer JD, Hayes KC, Alexander IJ. Knee joint effusion and quadriceps reflex inhibition in man. Archives of physical medicine and rehabilitation. 1984;65(4):171.

46. Logan CA, O’Brien LT, LaPrade RF. Post operative rehabilitation of grade III medial collateral ligament injuries: evidence based rehabilitation and return to play. International journal of sports physical therapy. 2016;11(7):1177.

47. Draper V. Electromyographic biofeedback and recovery of quadriceps femoris muscle function following anterior cruciate ligament reconstruction. Physical Therapy. 1990;70(1):11-17.

48. Rutherford DI, Hubley-Kozey CL, Stanish WD. Knee effusion affects knee mechanics and muscle activity during gait in individuals with knee osteoarthritis. Osteoarthritis and cartilage. 2012;20(9):974-981.

49. Andrew TL. Closed Kinetic Chain Exercise. A Comprehensive Guide to Multiple-Joint Exercises. Journal of Chiropractic Medicine. 2002;1(4):200.

50. Wilke J, Krause F, Vogt L, Banzer W. What is evidence-based about myofascial chains: a systematic review. Archives of physical medicine and rehabilitation. 2016;97(3):454-461.

51. Myers T, Frederick C. Stretching and fascia. In: Fascia: The Tensional Network of the Human Body. Elsevier; 2012:433-439.

52. Harrison RA, Hillman M, Bulstrode SI. Loading of the lower limb when walking partially immersed: implications for clinical practice. Physiotherapy. 1992;78(3):164-166.

53. Torres-Ronda L, i del Alcázar XS. The properties of water and their applications for training. Journal of human kinetics. 2014;44(1):237-248.
54. Frisbie DD, Oxford JT, Southwood L, et al. Early events in cartilage repair after subchondral bone microfracture. Clinical Orthopaedics and Related Research $^{\circledR}$. 2003;407:215-227.

55. Grande DA, Pitman MI, Peterson L, Menche D, Klein M. The repair of experimentally produced defects in rabbit articular cartilage by autologous chondrocyte transplantation. Journal of Orthopaedic Research. 1989;7(2):208-218.

56. Hangody L. Autogenous osteochondral graft technique for replacing knee cartilage defects in dogs. Orthopedics. 1997;5:175-181.

57. Nam EK, Makhsous M, Koh J, Bowen M, Nuber G, Zhang L-Q. Biomechanical and histological evaluation of osteochondral transplantation in a rabbit model. The American Journal of Sports Medicine. 2004;32(2):308-316.

58. Lepley LK, Davi SM, Hunt ER, et al. Morphology and Anabolic Response of Skeletal Muscles Subjected to Eccentrically or Concentrically Biased Exercise. Journal of Athletic Training. 2020;55(4):336-342.

59. Balazs GC, Wang D, Burge AJ, Sinatro AL, Wong AC, Williams III RJ. Return to play among elite basketball players after osteochondral allograft transplantation of full-thickness cartilage lesions. Orthopaedic journal of sports medicine. 2018;6(7):2325967118786941.

60. Makinejad MD, Abu Osman NA, Wan Abas WAB, Bayat M. Preliminary analysis of knee stress in full extension landing. Clinics. 2013;68(9):1180-1188.

61. McCarthy MA, Meyer MA, Weber AE, et al. Can competitive athletes return to high-level play after osteochondral allograft transplantation of the knee? Arthroscopy: The Journal of Arthroscopic \& Related Surgery. 2017;33(9):1712-1717.

62. Kuenze C, Hertel J, Hart JM. Effects of exercise on lower extremity muscle function after anterior cruciate ligament reconstruction. Journal of sport rehabilitation. 2013;22(1):33-40.

63. Dalton EC, Pfile KR, Weniger GR, Ingersoll CD, Herman D, Hart JM. Neuromuscular changes after aerobic exercise in people with anterior cruciate ligament-reconstructed knees. National Athletic Trainers' Association, Inc. 2011.

64. Grooms DR, Page SJ, Onate JA. Brain activation for knee movement measured days before second anterior cruciate ligament injury: neuroimaging in musculoskeletal medicine. Journal of athletic training. 2015;50(10):1005-1010. 
65. Guillot A, Kerautret Y, Queyrel F, Schobb W, Di Rienzo F. Foam Rolling and Joint Distraction with Elastic Band Training Performed for 5-7 Weeks Respectively Improve Lower Limb Flexibility. Journal of sports science \& medicine. 2019;18(1):160.

66. Kokkonen J, Nelson AG, Tarawhiti T, Buckingham $\mathrm{P}$, Winchester JB. Early-phase resistance training strength gains in novice lifters are enhanced by doing static stretching. The Journal of Strength \& Conditioning Research. 2010;24(2):502-506.

67. Romero-Franco N, Romero-Franco J, JiménezReyes P. Jogging and Practical-Duration Foam-Rolling Exercises and Range of Motion, Proprioception, and Vertical Jump in Athletes. Journal of Athletic Training. 2019;54(11):1171-1178.

68. Stanton R, Reaburn P. Exercise and the treatment of depression: a review of the exercise program variables. Journal of Science and Medicine in Sport. 2014;17(2):177-182.

69. Reilly T. The Science of Training-Soccer: A Scientific Approach to Developing Strength, Speed and Endurance. Routledge; 2006.

70. Tabata I. Tabata training: one of the most energetically effective high-intensity intermittent training methods. The Journal of Physiological Sciences. 2019;69(4):559-572.

71. Emberts T, Porcari J, Dobers-tein S, Steffen J, Foster C. Exercise intensity and energy expenditure of a tabata workout. Journal of sports science \& medicine. 2013;12(3):612.

72. Rebold MJ, Kobak MS, Otterstetter R. The influence of a Tabata interval training program using an aquatic underwater treadmill on various performance variables. The Journal of Strength \& Conditioning Research. 2013;27(12):3419-3425.

73. Putukian M. The psychological response to injury in student athletes: a narrative review with a focus on mental health. British Journal of Sports Medicine. 2016;50(3):145-148.

74. Garcia GH, Wu H-H, Park MJ, et al. Depression symptomatology and anterior cruciate ligament injury: incidence and effect on functional outcome-a prospective cohort study. The American journal of sports medicine. 2016;44(3):572-579.

75. Laskowski ER, Newcomer-Aney K, Smith J. Refining rehabilitation with proprioception training: expediting return to play. The physician and sportsmedicine. 1997;25(10):89-102.
76. Baltaci G, Kohl HW. Does proprioceptive training during knee and ankle rehabilitation improve outcome? Physical therapy reviews. 2003;8(1):5-16.

77. Cooper RL, Taylor NF, Feller JA. A systematic review of the effect of proprioceptive and balance exercises on people with an injured or reconstructed anterior cruciate ligament. Research in sports medicine. 2005;13(2):163-178.

78. Malliaras P, Cook J, Purdam C, Rio E. Patellar tendinopathy: clinical diagnosis, load management, and advice for challenging case presentations. journal of orthopaedic \& sports physical therapy. 2015;45(11):887-898.

79. Mithoefer K, Hambly K, Logerstedt D, Ricci M, Silvers H, Villa SD. Current concepts for rehabilitation and return to sport after knee articular cartilage repair in the athlete. journal of orthopaedic \& sports physical therapy. 2012;42(3):254-273.

80. Cotter EJ, Frank RM, Wang KC, Cole BJ. Rehabilitation and Return to Play Following Osteochondral Allograft Transplantation in the Knee. Operative Techniques in Sports Medicine. 2017;25(3):208-213.

81. Haber DB, Logan CA, Murphy CP, Sanchez A, LaPrade RF, Provencher MT. OSTEOCHONDRAL ALLOGRAFT TRANSPLANTATION for the KNEE: POST-OPERATIVE REHABILITATION. International journal of sports physical therapy. 2019;14(3):487.

82. Asadi A, Ramirez-Campillo R, Meylan C, Nakamura FY, Cañas-Jamett R, Izquierdo M. Effects of volume-based overload plyometric training on maximal-intensity exercise adaptations in young basketball players. The Journal of sports medicine and physical fitness. 2016;57(12):1557-1563.

83. Wang D, Lin KM, Burge AJ, Balazs GC, Williams RJ III. Bone Marrow Aspirate Concentrate Does Not Improve Osseous Integration of Osteochondral Allografts for the Treatment of Chondral Defects in the Knee at 6 and 12 Months: A Comparative Magnetic Resonance Imaging Analysis. Am J Sports Med. 2019;47(2):339-346. doi:10.1177/036354651881 $\underline{3915}$

84. Wang D, Chiaia T, Cavanaugh JT, Rodeo SA. Team Approach: Return to Play After Anterior Cruciate Ligament Reconstruction. JBJS Rev. 2019;7(1):e1. do i:10.2106/JBJS.RVW.18.00003

85. Frank RM, Lee S, Levy D, et al. Osteochondral allograft transplantation of the knee: Analysis of failures at 5 years. Am J Sports Med. 2017;45(4):864-874. doi:10.1177/0363546516676072 
86. Marom N, Wang D, Patel S, Williams RJ III. Return to Play After Bipolar Patellofemoral Osteochondral Allograft Transplantation for a Professional Basketball Player: A Case Report. JBJS case connector. 2019;9(3):e0291. 